\title{
Laparoscopic adrenalectomy: preoperative data, surgical technique and clinical outcomes
}

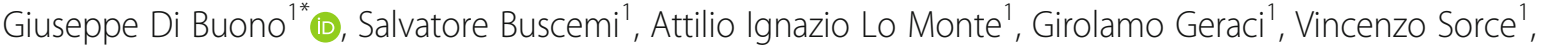 \\ Roberto Citarrella², Eliana Gulotta', Vincenzo Davide Palumbo', Salvatore Fazzotta', Leonardo Gulotta', \\ Domenico Albano ${ }^{3}$, Massimo Galia ${ }^{3}$, Giorgio Romano ${ }^{1,3}$ and Antonino Agrusa ${ }^{1,3}$
}

\begin{abstract}
Background: laparoscopic adrenalectomy has become the standard treatment for adrenal lesions. The better clinical outcoms of laparoscopic technique are valid for treatment of small benign masses $(<5-6 \mathrm{~cm})$, instead there are still open questions in literature regarding the correct management of larger lesions $(>6 \mathrm{~cm})$ or in case of potentially malignant adrenal tumors. The aim of this study is to evaluate the outcomes of laparoscopic adrenalectomy in a referral surgical department for endocrine surgery.

Methods: at the University Hospital Policlinico "P. Giaccone" of Palermo between January 2010 and December 2017 we performed a total of 81 laparoscopic adrenalectomy. We created a retrospective database with analysis of patients data, morphologic and hormonal characteristics of adrenal lesions, surgical procedures and postoperative results with histological diagnosis and complications.

Results: Mean size of adrenal neoplasm was $7,5 \mathrm{~cm}$ (range 1.5 to $18 \mathrm{~cm}$ ). The mean operative time was 145 min (range 75-240). In statistical analysis lenght of surgery was correlated to the lesion diameter $(p<0.05)$ but not with pre-operative features or histological results. 5 intraoperative complications occurred. Among these patients 4 presented bleeding and 1 a diaphagmatic lesion. No conversion to open surgery was necessary and no intraoperative blood transfusion were required. Mean estimated blood loss was $95 \mathrm{ml}$ (range 50-350). There was no capsular disruption during adrenal dissection. Mean length of hospital stay was 3.7 days (range 3-6 days).

Conclusions: Laparoscopic adrenalectomy is a safe procedure with low rate of morbidity. An accurate preoperative radiological examination is fundamental to obtain a stringent patients selection. The lesion diameter is related to longer operative time and appeares as the main predictive parameter of intraoperative complications but these results are not statistically significant. On the other side secreting adrenal tumors require more attention in operative management without increased rate of postoperative complications.
\end{abstract}

Keywords: Laparoscopic adrenalectomy, Laparoscopic surgery, Adrenalectomy, Endocrine surgery, Cushing syndrome, Adrenal Incidentaloma

\footnotetext{
*Correspondence: giuseppe.dibuono@unipa.it

'Department of Surgical, Oncological and Oral Sciences (Di.Chir.On.S.),

University of Palermo, Italy, Via L. Giuffrè, 5, 90127 Palermo, Italy

Full list of author information is available at the end of the article
}

(c) The Author(s). 2019 Open Access This article is distributed under the terms of the Creative Commons Attribution 4.0 International License (http://creativecommons.org/licenses/by/4.0/), which permits unrestricted use, distribution, and reproduction in any medium, provided you give appropriate credit to the original author(s) and the source, provide a link to the Creative Commons license, and indicate if changes were made. The Creative Commons Public Domain Dedication waiver (http://creativecommons.org/publicdomain/zero/1.0/) applies to the data made available in this article, unless otherwise stated. 


\section{Background}

Since first description in 1992 by Gagner laparoscopic adrenalectomy (LA) has become the standard treatment for adrenal lesions [1]. Over the years several studies have identified the advantages of laparoscopic technique with reduction in morbidity and perioperative mortality due to less operative blood loss, lower complication rates, less postoperative pain, shorter hospital stay and better cosmetic results when compared with open adrenalectomy (OA) [2]. On the basis of positive outcomes of LA performed with traditional lateral transperitoneal approach, other surgical techniques have also been developed as posterior retroperitoneoscopic adrenalectomy (PRA) or robotic adrenalectomy (RA) [3-5] These excellent clinical achievements are valid for treatment of small benign masses $(<5-6 \mathrm{~cm})$, instead there are still open questions in literature regarding the correct management of larger lesions $(>6 \mathrm{~cm})$ or in case of potentially malignant adrenal tumors [6]. In these patients increases the risk of incomplete resection, capsular disruption, local recurrence and peritoneal dissemination [7].With the enlarged diffusion of laparoscopy many surgeons carry out LA even if they have poor experience with adrenal pathologies. On the basis of these considerations, the aim of this study is to evaluate the outcomes of LA in a referral surgical department for endocrine surgery.

\section{Methods}

In our Department of General and Emergency Surgery at the University Hospital Policlinico "P. Giaccone" of Palermo between January 2010 and December 2017 we performed a total of $81 \mathrm{LA}$. We created a retrospective database with analysis of patients demographic data, previous abdominal surgery, American Society of Anesthesiologists (ASA) score, morphologic and hormonal characteristics of adrenal lesions, surgical procedures, postoperative results, histological diagnosis and in particular cases also mid- and long-term follow-up. Only patients with certain primary elements of malignant adrenal neoplasm on radiological examination like local invasion and/or distant metastases were excluded from the study because underwent to OA [8]. All surgical procedures were performed by the same surgical team experienced in endocrine and laparoscopic surgery in order to obtain a standard technique.

\section{Preoperative evaluation}

Before surgery all patients underwent a complete preoperative checkup including cardiological counseling for evaluating general performance status and endocrine study with complete hormonal tests to identify functioning adrenal tumors. Today there is no consensus on the optimal diagnostic approach to the incidentally discovered adrenal masses. For the diagnosis of Cushing's syndrome we carried out urine free cortisol test, serum cortisol and ACTH at 8 a.m. and 6 p.m. (ACTH drawn into an EDTA tube, cooled). We also used dexamethasone suppression test with evaluation of cortisol secretion suppression after oral administration of $1 \mathrm{mg}$ dexamethasone at 11-12 p.m. The cortisol serum concentration was measured on the following day in the morning after overnight fasting (at 8-9 a.m.). In case of aldosteronoma we dosed aldosterone serum concentration and plasma renin activity (PRA) in upright position as indirect indicator of renin secretion. In our experience we did not perform adrenal venous sampling to discern between unilateral and bilateral aldosterone overproduction because we had no cases of bilateral lesions. We examined the adrenal medullary function with dosage of fractionated urinary metanephrines and catecholamines using High Performance Liquid Chromatography (HPLC) technique. With the same HPLC we tested dehydroepiandrosterone (DHEA) and dehydroepiandrosterone sulphate (DHEA-S) in patients with hyperandrogenism. In order to obtain blood pressure stabilization a pharmacological preoperative treatment was done by alpha-1 blocker or calcic inhibitors in case of pheocromocytoma (PCC); we used spironolactone and potassium for Conn's syndrome. In all cases we administered antithrombotic and antibiotic prophylaxis. We carried out routinely an abdominal contrast-enhanced Computed tomography (CT) scan to study the morphological characteristics and size of the lesion. Abdominal magnetic resonance imaging (MRI) was used in selected patients with unclear features to the CT scan. We analyzed the presence of fat components within the lesions through frequency selective fat suppression and chemical shift suppression or differences in cellularity on $\mathrm{T}_{1}$ and $\mathrm{T}_{2}$ weighted sequences [8]. We used functional imaging as $\left[{ }^{75} \mathrm{se}\right.$ ]cholesterol, $\left[{ }^{131} \mathrm{I}\right]$ metaiodobenzylguanidine scintigraphy or $\left[{ }^{18} \mathrm{~F}\right]$ fluorodeoxyglucose positron emission tomography (FDG-PET) only if necessary such as in case of bilateral secreting lesions. A diagnosis of adrenal cortical carcinoma (ACC) was based on the patients history (e.g. hormonal symptoms with virilizing tumor) and radiologic findings. We excluded from this study patients with imaging features of malignancy as local infiltration of the surrounding structures, venous invasion or systemic metastasis. In these cases we performed OA. In addiction we also excluded from the study a right LA for large bleeding angiomyolipoma performed in urgent setting. The mere size of the lesion was not considered a signal of malignant lesion [9]. Indication for LA included hormone secreting tumors (Cushing's lesion, Conn's syndrome, pheochromocytomas) and all nonfunctioning tumors larger than $4 \mathrm{~cm}$.

\section{Surgical procedure}

LA was carried out with a transperitoneal approach with the patient in the lateral decubitus position with an 
inclination of $50-60^{\circ}$ relative to the operating table which was broken to extend the space between the last rib and the iliac crest [10]. We always used Veress needle to induce pneumoperitoneum also in case of previous abdominal surgery. For right adrenalectomy we positioned four trocars in the right subcostal region. The right lobe of the liver was mobilized by division of triangular and coronary ligament to expose the adrenal loggia. Then the posterior peritoneum overlying the right adrenal gland, in Albarran-Chatelin space, was dissected using Harmonic scalpel ${ }^{\mathrm{m}}$ (Ethicon Endo Surgery INC - Johnson \& Johnson, NJ, USA). The tissue dissection began along the lateral border of the inferior vena cava: we used right renal vein as anatomic landmark and then we identified a short adrenal vein that was clipped and divided. After vascular ligation we reached the ileopsoas muscle plane and the adrenal gland was mobilized until it was completely free. For left-side adrenal resection we positioned three trocars in the left subcostal region. The procedure began with adequate mobilization of splenic flexure of the colon and then we divided splenocolic and splenophrenic ligament to medially mobilize the splenicpancreatic block. On the contrary of the right side where we had a well defined Albarran-Chatelin space, for the left side the landmarks were more difficult to identify. We could consider a quadrilater between spleen and pancreatic tail, upper pole of the kidney, left renal vein and ileopsoas muscle. The peritoneal dissection was done from up-to-down until the left renal vein was reached and from this we identified adrenal vein that was clipped and divided. In some cases we used the diaphragmatic vein as landmarks. Completed the vascular dissection the resection proceeded as previously described for the right adrenal gland on the posterior muscular plane from upper pole of the kidney to the diaphragm with the aim to empty the adrenal loggia. On the left side we always used Tisseel $^{\text {ma }}$ (Baxter International Inc. - Deerfield, Illinois, USA) for repositioning splenic-pancreatic block in order to avoid wandering spleen. At the end of the procedure surgical specimens were positioned in endo-bag and removed through the operative trocar or in case of large lesions with sovrapubic mini-laparotomy to improve cosmesis and prevent incisional hernia $[11,12]$. The total operative time, the partial surgical times (exposure of the adrenal loggia, identification of the adrenal vein, dissection time) and intraoperative complications were noted respectively in the operative report and in the video recordings of the procedure.

\section{Postoperative management}

Postoperative pharmacological management changed according to the hormonal diagnosis of the adrenal mass. In all patients normal diet and mobilization started on the first postoperative day. We positioned abdominal drainage only in large adrenal masses and difficult surgical procedures. In these cases drainage was removed on the first or second postoperative day. Postoperative complications, defined as an unexpected postoperative course, were graded according to the Dindo-Clavien classification [13]. For statistical analysis we only considered postoperative medical or surgical complications with grade equal or superior to 2 .

\section{Statistical analysis}

Statistical analysis were performed with SPSS 20.0 (SPSS Inc., Arlington, Virginia). Continuous variable was expressed as the mean. Categorical Data were compared with Chi-square analysis and continous data with Student $t$ test. A $p$ value $<0.05$ was considered statistically significant.

\section{Results}

Between January 2010 and December 2017, 81 patients (34 male and 47 female) with a mean age of 55.4 years (range 38-81) underwent to LA, 50 on the right side and 31 on the left side. We did not treat bilateral lesions. Patients and tumors characteristics are summarized in Table 1. We registered that the major part of patients (73 cases) had ASA score 3 with several comorbidities. In 23 cases $(28.4 \%)$ we found previous abdominal or retroperitoneal surgery including $9(11.1 \%)$ appendectomies, $10(12,3 \%)$ gynecological procedure and $4(4.9 \%)$ different surgeries (2 laparoscopic cholecystectomies, 1 open right hemicolectomy for cancer and 1 open surgical procedure for renal stones) [14]. Indications for LA included 18 (22.2\%) Cushing's syndrome, 10 (12.3\%) Conn's syndrome, 14 (17.3\%) pheochromocytomas, 1 (1.2\%) adrenal metastasis, 2 (2.5\%) adrenocortical carcinomas (ACC), 17 (21\%) non-secreting adenomas, 11 (13.6\%) myelolipomas, 3 (3.7\%) adrenal cysts, 4 (4.9\%) hemangiomas and 1 (1.2\%) nodular hyperplasia [15]. Histological examination showed inside the Cushing's syndrome 2 adrenal cortical carcinomas. Inside the 14 pheochromocytomas 2 were malignant. We also found a cystic pheochromocytoma with histological signs of malignancy in a patients with preoperative diagnosis of adrenal cyst. The lesion diagnosed as metastasis in patient with history of endometrial cancer was really primary ACC (Table 2).

Details of procedure are reported in Table 3. Mean size of adrenal neoplasm was $7,5 \mathrm{~cm}$ (range 1.5 to $18 \mathrm{~cm}$ ). Aldosteronoma was associated with the smallest size $(1.5 \mathrm{~cm})$ while myelolipoma was the largest observed mass $(18 \mathrm{~cm})$. The mean operative time was $145 \mathrm{~min}$ (range 75-240). In statistical analysis lenght of surgery was correlated to the lesion diameter $(p<0.05)$ but not with pre-operative features or histological results. With evaluation of the video recordings of the surgical procedures we also took into 
Table 1 Demographic characteristcs of patients and indications for surgery

\begin{tabular}{ll}
\hline & Mean; $n$ (\%) \\
\hline Sex (M/F) & $34 / 47(42 \% / 58 \%)$ \\
ASA score & $55.4($ range 38-81) \\
1 & \\
2 & - \\
3 & $5(6.2 \%)$ \\
4 & $73(90.1 \%)$ \\
Previous abdominal surgery & $3(3.7 \%)$ \\
- appendectomies & \\
- gynecological surgery & $9(11.1 \%)$ \\
- other procedures & $10(12.3 \%)$ \\
Pre-operative diagnosis & $4(5 \%)$ \\
- Cushing's syndrome & \\
- Pheochromocytoma & $18(22.2 \%)$ \\
- Conn's syndrome & $14(17.3 \%)$ \\
- Non-secreting adenoma & $10(12.3 \%)$ \\
- Myelolipoma & $17(21 \%)$ \\
- Adrenal cyst & $11(13.6 \%)$ \\
- Hemangioma & $3(3.7 \%)$ \\
- Nodular Hyperplasia & $4(4.9 \%)$ \\
- Adrenocortical carcinoma & $1(1.2 \%)$ \\
- Metastasis & $2(2.5 \%)$ \\
\hline
\end{tabular}

consideration the partial operative times: exposure of the adrenal loggia, identification of the adrenal vein and dissection time. The results showed that in the functioning masses and in particular in pheochromocytomas was greater the time of identification of the adrenal vein. In the large adrenal masses $(>6 \mathrm{~cm})$ all three partial times were increased but above all the adequate exposure of the adrenal loggia. 5 (6.2\%) intraoperative complications occurred.

Table 2 Histological diagnosis

\begin{tabular}{ll}
\hline & $n(\%)$ \\
\hline Cortisol-producing adenoma & $16(19.7 \%)$ \\
Aldosterone-producing adenoma & $12(14.8 \%)$ \\
Non-functional adenoma & $10(12.5 \%)$ \\
Myelolipoma & $17(21 \%)$ \\
Adrenal cyst & $11(13.6 \%)$ \\
Hemangioma & $2(2.5 \%)$ \\
Nodular Hyperplasia & $4(4.9 \%)$ \\
Adrenocortical carcinoma & $1(1.2 \%)$ \\
Malignant Pheochromocytoma & $5(6.2 \%)$ \\
Metastasis & $3(3.7 \%)$ \\
\hline
\end{tabular}

Table 3 Details of surgical procedures and postoperative complications

\begin{tabular}{ll}
\hline & Mean; $n$ (\%) \\
\hline Adrenalectomy & $50(61.7 \%)$ \\
- Right & $31(38.3 \%)$ \\
- Left & - \\
- Bilateral & 145 min (range 75-240) \\
Operative time & $7.5 \mathrm{~cm}$ (range 1.5-18) \\
Lesion diameter & - \\
Conversion to open surgery & \\
Intraoperative complication & $3(3.7 \%)$ \\
- Bleeding & - \\
- Intraoperative blood transfusion & $2(2.5 \%)$ \\
- Organ lesion & \\
Postoperative complication & $1(1.2 \%)$ \\
- Blood transfusion & $3(3.7 \%)$ \\
- Respiratory disease &
\end{tabular}

Among these patients 4 presented bleeding: 1 vena cava injury treated with intracorporeal sutures and positioning of pre-rolled TachoSil ${ }^{\oplus} ; 1$ from a small hepatic accessory vein that was isolated and clipped; 1 caused from a spleen injury during left adrenalectomy, in this case hemostasis was obtained with use of hemostatic matrix (Floseal ${ }^{\circledR}$ ); 1 from peri-renal tissue solved by positioning of Hemopatch ${ }^{\odot}$. In another patient with a large right adrenal masses $(14 \mathrm{~cm})$ we observed a diaphagmatic lesion treated with suture and intra-corporeal knotting with no transthoracic drainage [16, 17]. No conversion to open surgery was necessary and no intraoperative blood transfusion were required. Mean estimated blood loss was $95 \mathrm{ml}$ (range 50-350). Hemodynamic change with intraoperative hypertension occurred in 2 cases during pheochromocitomas removal without particular complications. There was no capsular disruption during adrenal dissection. There was none postoperative death. According to the Dindo-Clavien classification [13] for statistical analysis we only considered postoperative medical or surgical complications with grade equal or superior to 2 . We excluded 4 cases of sovrapubic wound infections open at the patient bedside (Grade 1). In one case we observed wound hematoma that required postoperative blood transfusion but not surgical intervention (Grade 2). In 3 patients was necessary prolonged antibiotic intake after hospital discharge due to localized pneumonia (Grade 2) None patient underwent a reoperation due to complications (Grade 3). In the statistical analysis there was no significant correlation between mean tumor size, histological type, intraoperative complication and postoperative outcome $(p$ value $>0.05)$. Only mean operative time resulted significant longer in large adrenal tumors $(>6 \mathrm{~cm})$. Mean length of hospital stay was 3.7 days (range 3-6 days). Mean follow up was 38.5 
months (range 3-72 months). All patients with malignant pheochromocytoma and adrenal cortical cancer were still alive after mean follow-up of 26,2 months (range 2-70). No local recurrence and port-side metastasis was noted.

\section{Discussion}

Since 1992 LA has become the standard treatment in patients with small benign adrenal masses [1]. When comparing with open technique, LA offered better clinical outcomes, reduced surgical trauma, lower perioperative morbidity and mortality, shorten hospitalization and better cosmetic results [2]. In order to reduce surgical trauma and improvement clinical postoperative outcome several authors developed posterior retroperitoneoscopic adrenalectomy (PRA). A randomized clinical trial by Barczynski et al. [18] showed excellent results of both techniques, anterior and posterior, in unilateral small tumors with statistically significant advantage of PRA in operative time, blood loss and postoperative course. However, the retroperitoneal approach reduced its benefits in the case of larger adrenal masses, so this approach could be preferred for bilateral small lesions and for patients with multiple past abdominal surgery that increased the risk of intraoperative complications and rate of conversion to the open surgery [19]. Laparoscopic surgery was also more difficult to learn than open surgery because required different psychomotor skills. Robotic adrenalectomy (RA) presented multiple advantages with three-dimensional vision and increased degrees of freedom of the surgical instruments. A recent meta-analysis [20] that included 798 patients compared operative parameters and clinical outcomes between RA and LA. The authors concluded that RA was a safe and feasible technique with reduced blood loss and shorter hospital stay than LA. Laparoscopic approach seemed to be a more rapid technique when comparing to RA. On the other hand, some authors considered the use of 3D laparoscopic technology with a traditional transperitoneal approach so as to combine the advantages of a standardized and diffused surgical procedure with an improved vision [21]. These authors analyzed LA for particular deep location of adrenal loggia with theoretical maximum advantage of a 3D system. The results showed the better visualization in depth perception with effect on surgical precision but without significant differences in term of operative time and intraoperative complications $[22,23]$. In our study we registered pre-operative data like ASA score, radiological features and hormonal tests. In literature age and ASA score were direct related to increased of length of hospital stay and postoperative complications [24]. Radiological features and tumor size appeared as a very important predictive parameter of outcome. The results showed the large adrenal masses $(>6$ $\mathrm{cm}$ ) were associated with duration of surgery and with an increased risk of intraoperative incident. Many author reported lesion diameter over $5-6 \mathrm{~cm}$ as independent predictive factors for conversion $[25,26]$. Functioning masses and in particular pheochromocytomas required longer operative time to identify the adrenal vein but these differences were no statistically significant. From analysis of partial operative time we also demonstrated that in large adrenal masses significantly increased the time necessary to approach the adrenal loggia. First exposure of adrenal gland by section of triangular and coronary liver ligament on the right side and splenocolic and splenophrenic ligament on the left side must be performed carefully in order not to damage diaphragm, spleen and pancreatic tail. Bleeding was the main intraoperative complications and injuries of the vena cava, renal vein or hepatic vein represented a real dangerous situation with increased conversion rate [27].We did not report conversion to open surgery. In case of intraoperative complications we performed a conservative laparoscopic management of vascular, splenic and diaphragmatic injuries. The conversion instead was mandatory in case of intraoperative evidences of malignancy like periadrenal tissue infiltration or vascular invasion. We considered capsular disruption as an intraoperative complication too. Literature data suggested that the main limitation during laparoscopic dissection for large and potentially malign adrenal tumors was incomplete resection and capsular disruption with increased risk of local recurrence and intra-abdominal neoplastic dissemination [28], but the tumor size per se could not be considered as an absolute controindication to LA. A correct preoperative patients selection and a meticulous surgical technique could limit that risk. Postoperative complication rate was $5 \%$ with one blood transfusion and three respiratory diseases. According to DindoClavien scale rate we considered medical or surgical complications with grade $\geq 2$ for statistical analysis with no significant correlation between mean tumor size, histological type and postoperative outcome $(p$ value $>0.05)$. Coste $\mathrm{T}$. et al. [24] reported that postoperative medical complications were mainly respiratory diseases and various infections.

\section{Conclusion}

In this study we used retrospective data like demographic, radiological and hormonal characteristics and prospective parameters such as partial time of surgical procedures and evaluation of intraoperative complications obtain from recordings video of LA. The study period was limited from January 2010 to December 2017 and the all procedures were performed in a single center by an experienced endocrine and laparoscopic surgical team. The limitations were related to lower rate of postoperative complication with not significant results in terms of association between preoperative characteristics and postoperative outcomes. Nevertheless, it is possible 
to confirm that LA is a safe procedure with low rate of morbidity. An accurate preoperative radiological examination is fundamental to obtain a stringent patients selection. The lesion diameter is related to longer operative time and appeares as the main predictive parameter of intraoperative complications but these results are not statistically significant. On the other side secreting adrenal tumors require more attention in operative management without increased rate of postoperative complications.

\section{Abbreviations \\ ACC: Adrenal Cortical Carcinoma; BP: Blood Pressure; LA: Laparoscopic Adrenalectomy; OA: Open Adrenalectomy; PCC: Pheochromocytoma; PRA: Posterior Retroperitoneoscopic Adrenalectomy; RA: Robotic Adrenalectomy}

\section{Acknowledgements}

Not Applicable.

\section{Funding}

This article did not receive sponsorship for publication.

\section{Availability of data and materials}

The datasets used and/or analysed during the current study are available from the corresponding author on reasonable request.

The datasets used and/or analysed during the current study are available from the Department of Surgical, Oncological and Oral Sciences (Di.Chir.On.S.) University of Palermo, Via L. Giuffrè 5-90,127 Palermo, on reasonable request.

\section{About this supplement}

This article has been published as part of BMC Surgery Volume 18 Supplement 1 , 2018: Updates and New Technology in Endocrine Surgery. The full contents of the supplement are available online at https://bmcsurg.biomedcentral.com/articles/ supplements/volume-18-supplement-1.

\section{Authors' contributions}

All of the authors have read an approved the final manuscript. All authors contributed significantly to the present research. DBG: Participated substantially in conception, design and execution of the study and in the analysis and interpretation of the data; also participated substantially in the drafting and editing of the manuscript. BS: Participated substantially in conception, design and execution of the study and in the analysis and interpretation of the data. LMAI: Participated substantially in conception, design and execution of the study and in the analysis and interpretation of the data. GG: Participated substantially in conception, design and execution of the study and in the analysis and interpretation of the data. SV: Participated substantially in conception, design and execution of the study and in the analysis and interpretation of the data. CR: Participated substantially in conception, design and execution of the study and in the analysis and interpretation of the data. GE: Participated substantially in conception, design and execution of the study and in the analysis and interpretation of the data. PVD: Participated substantially in conception, design and execution of the study and in the analysis and interpretation of the data. FS: Participated substantially in conception, design and execution of the study and in the analysis and interpretation of the data. GL: Participated substantially in conception, design and execution of the study and in the analysis and interpretation of the data. AD: Participated substantially in conception, design and execution of the study and in the analysis and interpretation of the data. GM: Participated substantially in conception, design and execution of the study and in the analysis and interpretation of the data. RG: Participated substantially in conception, design and execution of the study and in the analysis and interpretation of the data. AA: Participated substantially in conception, design and execution of the study and in the analysis and interpretation of the data; also participated substantially in the drafting and editing of the manuscript.

\section{Ethics approval and consent to participate}

Ethical approval for the study was given by University Hospital Policlinico "P. Giaccone" of Palermo.

\section{Consent for publication}

All patients gave written informed consent to publish their data.

\section{Competing interests}

The authors declare that they have no competing interests.

\section{Publisher's Note}

Springer Nature remains neutral with regard to jurisdictional claims in published maps and institutional affiliations.

\section{Author details}

'Department of Surgical, Oncological and Oral Sciences (Di.Chir.On.S.), University of Palermo, Italy, Via L. Giuffrè, 5, 90127 Palermo, Italy.

${ }^{2}$ Department of Experimental Biomedicine and Clinical Neurosciences, University of Palermo, Palermo, Italy. ${ }^{3}$ Department of Radiology, University of Palermo, Palermo, Italy.

Received: 25 September 2018 Accepted: 7 December 2018 Published: 24 April 2019

\section{References}

1. Gagner M, Lacroix A, Bolte E. Laparoscopic adrenalectomy in Cushing's syndrome and pheochromocytoma. N Engl J Med. 1992;327:1033.

2. Hazzan D, Shiloni E, Golijanin D, Jurim O, Gross D, Reissman P. Laparoscopic vs open adrenalectomy for benign adrenal neoplasm. Surg Endosc. 2001;15: $1356-8$.

3. Chai YJ, Yu HW, Song RY, Kim SJ, Choi JY, Lee KE. Lateral Transperitoneal adrenalectomy versus posterior Retroperitoneoscopic adrenalectomy for benign adrenal gland disease: randomized controlled trial at a single tertiary medical center. Ann Surg. 2017 Nov 20. https://doi.org/10.1097/SLA.0000000000002603.

4. Conzo G, Tartaglia E, Gambardella C, Esposito D, Sciascia V, Mauriello C, Nunziata A, Siciliano G, Izzo G, Cavallo F, Thomas G, Musella M, Santini L. Minimally invasive approach for adrenal lesions: systematic review of laparoscopic versus retroperitoneoscopic adrenalectomy and assessment of risk factors for complications. Int J Surg. 2016;28(Suppl 1):S118-23. https:// doi.org/10.1016/j.jijsu.2015.12.042.

5. Morelli L, Tartaglia D, Bronzoni J, Palmeri M, Guadagni S, Di Franco G, Gennai A, Bianchini M, Bastiani L, Moglia A, Ferrari V, Fommei E, Pietrabissa A, Di Candio G, Mosca F. Robotic assisted versus pure laparoscopic surgery of the adrenal glands: a case-control study comparing surgical techniques. Langenbeck's Arch Surg. 2016;401(7):999-1006.

6. Conzo G, Musella M, Corcione F, De Palma M, Avenia N, Milone M, Della Pietra C, Palazzo A, Parmeggiani D, Pasquali D, Sinisi A, Santini L. Laparoscopic treatment of pheochromocytomas smaller or larger than $6 \mathrm{~cm}$ a clinical retrospective study on 44 patients. Laparoscopic adrenalectomy for pheochromocytoma Ann Ital Chir. 2012:84:417-22.

7. Agrusa A, Romano G, Frazzetta G, Chianetta D, Sorce V, Di Buono G, Gulotta G. Laparoscopic adrenalectomy for large adrenal masses: single team experience. Int J Surg. 2014;12(1):S72-4. https://doi.org/10.1016/j.jiju.2014.05.050.

8. Galia M, Albano D, Bruno A, Agrusa A, Romano G, Di Buono G, Agnello F, Salvaggio G, La Grutta L, Midiri M, Lagalla R. Imaging features of solid renal masses. Br J Radiol. 2017;90(1077):20170077. https://doi.org/10.1259/bjr.20170077.

9. Sturgeon C, Shen WT, Clark OH, et al. Risk assessment in 457 adrenal cortical carcinomas: how much does tumor size predict the likelihood of malignancy? J Am Coll Surg. 2006;202:423-30.

10. Agrusa A, Romano G, De Vita G, Frazzetta G, Chianetta D, Di Buono G, Gulotta G. Adrenal gunshot wound: laparoscopic approach. Report of a case. Int I Surg Case Rep. 2014;5(2):70-2. https://doi.org/10.1016/j.jijscr.2013.12.020.

11. Romano G, Agrusa A, Chianetta D, Frazzetta G, Sorce V, Di Buono G, Gulotta G. Laparoscopic management of adrenal tumors: a four-years experience in a single center. Minerva Chir 2014; 69(2) 1:125-1:129.

12. Agrusa A, Romano G, Salamone G, Orlando E, Di Buono G, Chianetta D, Sorce V, Gulotta L, Galia M, Gulotta G. Large cavernous hemangioma of the adrenal gland: laparoscopic treatment. Report of a case. Int I Surg Case Rep. 2015;16:150-3. https://doi.org/10.1016/j.ijscr.2015.09.040.

13. Dindo D, Demartines N, Clavien PA. Classification of surgical complications: a new proposal with evaluation in a cohort of 6336 patients and results of a survey. Ann Surg. 2004 Aug;240(2):205-13.

14. Agrusa A, Romano G, Di Buono G, Frazzetta G, Chianetta D, Sorce V, Billone V. Cucinella G, Gulotta G. Acute appendicitis and endometriosis: retrospective analysis in emergency setting. GIOG 2013; 35(6):728-732. 
15. Agrusa A, Romano G, Dominguez $L$, Amato G, Citarrella R, Vernuccio L, Di Buono G, Sorce V, Gulotta L, Galia M, Mansueto P, Gulotta G. Adrenal cavernous hemangioma: which correct decision making process? Acta Medica Mediterranea. 2016;32:385-9. https://doi.org/10.19193/039363842016_2_58.

16. Agrusa A, Romano G, Chianetta D, De Vita G, Frazzetta G, Di Buono G, Sorce V, Gulotta G. Right diaphragmatic injury and lacerated liver during a penetrating abdominal trauma: case report and brief literature review. World J Emerg Surg. 2014;9:33. https://doi.org/10.1186/1749-7922-9-33.

17. Agrusa A, Frazzetta G, Chianetta D, Di Giovanni S, Gulotta L, Di Buno G, Sorce V, Romano G, Gulotta G. "Relaparoscopic" management of surgical complications: the experience of an emergency center. Surg Endosc. 2016; 30(7):2804-10. https://doi.org/10.1007/s00464-015-4558-2.

18. Barczyński M, Konturek A, Nowak W. Randomized clinical trial of posterior retroperitoneoscopic adrenalectomy versus lateral transperitoneal laparoscopic adrenalectomy with a 5-year follow-up. Ann Surg. 2014;260(5): 740-7; discussion 747-8. https://doi.org/10.1097/SLA.0000000000000982.

19. van Uitert A, d'Ancona FCH, Deinum J, Timmers HJLM, Langenhuijsen JF. Evaluating the learning curve for retroperitoneoscopic adrenalectomy in a high-volume center for laparoscopic adrenal surgery. Surg Endosc. 2017; 31(7):2771-5. https://doi.org/10.1007/s00464-016-5284-0.

20. Agrusa A, Romano G, Navarra G, Conzo G, Pantuso G, Di Buono G, Citarrella R, Galia M, Monte AL, Cucinella G, Gulotta G. Innovation in endocrine surgery: robotic versus laparoscopic adrenalectomy. Meta-analysis and systematic literature review. Oncotarget. 2017;8(60):102392-400. https://doi. org/10.18632/oncotarget.22059.

21. Currò G, La Malfa G, Caizzone A, Rampulla V, Navarra G. Three-dimensional (3D) versus two-dimensional (2D) laparoscopic bariatric surgery: a singlesurgeon prospective randomized comparative study. Obes Surg. 2015; 25(11):2120-4. https://doi.org/10.1007/s11695-015-1674-y.

22. Agrusa A, di Buono G, Chianetta D, Sorce V, Citarrella R, Galia M, Vernuccio L, Romano G, Gulotta G. Three-dimensional (3D) versus two-dimensional (2D) laparoscopic adrenalectomy: a case-control study. Int J Surg. 2016;28(1): S114-7. https://doi.org/10.1016/j.jisu.2015.12.055.

23. Agrusa A, Di Buono G, Buscemi S, Cucinella G, Romano G, Gulotta G. 3D laparoscopic surgery: a prospective clinical trial. Oncotarget. 2018;9(25): 17325-33. https://doi.org/10.18632/oncotarget.24669.

24. Coste T, Caiazzo R, Torres F, Vantyghem MC, Carnaille B, Pattou F, Cao CD, Douillard C. Laparoscopic adrenalectomy by transabdominal lateral approach: 20 years of experience. Surg Endosc. 2017;31(7):2743-51. https:// doi.org/10.1007/s00464-016-4830-0.

25. Conzo G, Gambardella C, Candela G, Sanguinetti A, Polistena A, Clarizia G, Patrone R, Di Capua F, Offi C, Musella M, lorio S, Bellastella G, Pasquali D, De Bellis A, Sinisi A, Avenia N. Single center experience with laparoscopic adrenalectomy on a large clinical series. BMC Surg. 2018;18(1):2. https://doi. org/10.1186/s12893-017-0333-8

26. Parnaby CN, Chong PS, Chisholm L, Farrow J, Connell JM, O'Dwyer PJ. The role of laparoscopic adrenalectomy for adrenal tumours of $6 \mathrm{~cm}$ or greater. Surg Endosc. 2008 Mar;22(3):617-21.

27. Gaujoux S, Bonnet S, Leconte M, Zohar S, Bertherat J, Bertagna X Dousset B. Risk factors for conversion and complications after unilateral laparoscopic adrenalectomy. Br J Surg. 2011;98(10):1392-9. https://doi. org/10.1002/bjs.7558.

28. Porpiglia F, Fiori C, Daffara F, Zaggia B, Bollito E, Volante M, Berruti A, Terzolo M. Retrospective evaluation of the outcome of open versus laparoscopic adrenalectomy for stage I and II adrenocortical cancer. Eur Urol. 2010;57(5):873-8. https://doi.org/10.1016/j.eururo.2010.01.036.

Ready to submit your research? Choose BMC and benefit from:

- fast, convenient online submission

- thorough peer review by experienced researchers in your field

- rapid publication on acceptance

- support for research data, including large and complex data types

- gold Open Access which fosters wider collaboration and increased citations

- maximum visibility for your research: over $100 \mathrm{M}$ website views per year

At BMC, research is always in progress.

Learn more biomedcentral.com/submissions 